\title{
Combating Fake Agro-Inputs Products in Tanzania using Mobile Phones
}

\author{
Deo Shao \\ Virtual Education Technology and Applications \\ The University of Dodoma \\ Dodoma, Tanzania
}

\author{
Steven Edward \\ Computer Science \\ The University of Dodoma \\ Dodoma, Tanzania
}

\begin{abstract}
Fake (Counterfeit) agro-inputs are causing myriad challenges to agricultural sectors in the developing countries by affecting the productivity rate. This paper analyzes the magnitude of the counterfeit agro-inputs and propose a system that integrates a mobile-based solution that helps the authentication of the agro-inputs products in Tanzania. A face to face interview with key informants in the agriculture sector and field data collection in one region were carried to understand the challenges in preventing the fake agro-inputs and awareness among stakeholders. The study has revealed that there is no trustworthy methods of verifying agro-inputs, the current methods such as expiration date and labels are weak and can be forged easily. The magnitude of counterfeit agro-inputs is rated by the respondents to be high. Crop seeds were found to be mostly counterfeited among other agro-inputs such as fertilizers, animal feeds and pesticides. The proposed system allows the stakeholders to authenticate the genuineness of the agricultural inputs through their mobile phones. This will tremendously boost confidence to farmers and greatly increase yields by buying hybrid seeds instead of replanting their own seeds. The evaluation study shows that the Agro-inputs Products Verification System (APVS) is feasible in Tanzanian settings and can significantly reduce the magnitude of counterfeit in agro-inputs products.
\end{abstract}

\section{General Terms}

ICT for Agriculture.

\section{Keywords}

Mobile phones; Counterfeit agro-inputs; Agro-ICT;

\section{INTRODUCTION}

Agriculture is one of the important sectors for the economies of African countries. It is a highly relied upon sector for non-oil exporting African countries such as Tanzania. The sector contributes for nearly $30 \%$ of the continents Gross Domestic Product (GDP) and 70\% of the continents population depends on agriculture to sustain their life. According to World Bank, agriculture is an important asset for achieving the Millennium Development Goals (MDG) and a means to reduce poverty in sub-Saharan Africa [1].

About $80 \%$ of the population in Tanzania lives in rural areas heavily dependent on agricultural production [2]. In 2003 agriculture accounted for half of the country's GDP, provided $51 \%$ of foreign exchange and employed $80 \%$ of the labour force. It accounts for half of the country's total GDP [3].

\begin{abstract}
Agricultural sector in Tanzania is facing myriad challenges that prevent it from moving forward. Among the challenges that impede the agricultural sector, fake and substandard agricultural inputs pose a serious stumbling block in the sectors progress. The government has been responding to these challenges by formulating strategies to reduce them. Examples of these strategies are campaigns such as 'Kilimo Kwanza' (Agriculture first). Kilimo Kwanza campaign aimed at igniting the sector by emphasizing on applying modern ways of farming [4].
\end{abstract}

The use of ICT to support farmers has been studied broadly by various scholars. ICT has seemed to be a gear to enable quick access to information and relevant knowledge and information that may improve agricultural productivity, reduce poverty and ensure food security in developing countries [5]. Access to information could enormously empower farmers to perform informed decision and practices in their farming. Slaymaker and Young [6] assessed the effectiveness of using radio to disseminate agricultural information in rural areas of Ghana and reported success story. The use of telecenters in India was found effective in improving rural livelihood [7].

A vast number of ICT solutions have emerged in recent years that support the agricultural value chain, including mobile applications. However, very little is being done to assess the quality of agricultural inputs such as hybrid seeds, fertilizers and pesticides. A quite big emphasize have been drawn in leveraging ICT for disseminating market information to farmers [8].

Despite the fact that studies have been conducted on the use of ICTs for agricultural development, these best practices are scattered in different countries, with various contexts and divides. In reality, not much has been done in the Tanzanian context[9].

Fake agricultural inputs such as seeds, fertilizers and pesticides can threaten the health of farmers and consumers, as well as posing risks to the natural environment [10]. Fighting counterfeit agro-inputs is a complex task which requires urgent actions by all stakeholders including regulatory authorities, the environmental protection agencies, as well as farmers and the food and pesticide industries.

Counterfeit agro-inputs is a global problem facing both developing and developed countries [11]. In Europe, the rate of counterfeit agro-inputs is reported be range from 5\% to $7 \%$. In China and India the rate is deemed to be $30 \%$ and $20 \%$ respectively [12][13].

Situation in Africa is critical. The fake agro-inputs in Africa are reported to make $15-20 \%$ of the agro-inputs 
market. Hot spots of these fake agro-inputs are said to be Egypt, West Africa, Uganda and Tanzania [14].

In Tanzania the situation is challenging as about $40 \%$ of agro-inputs(seeds, fertilizers and pesticides) are reported to be fake [15]. This has a negative impact on human health and ecosystems.

The Government has been emphasizing the use of improved seed for increased productivity; adoption by farmers is still low largely due to inadequate information, awareness and appreciation of the importance of improved seed. Low adoption translates into low purchased seed volumes. The existence of fake/adulterated seed under the cover of the names of big companies has disappoints farmers from buying the improved seeds (hybrid seeds) [3].This lead to low productivity due to reliance on saved seed.

Therefore the ICT-based solution for agro-inputs products verification will not only build confidence to hybrid crop seeds and fertilizers but also will improve rural livelihoods by increasing productivity through the use of modern practices.

\section{METHODOLOGY}

A list of publications were exhaustively reviewed to identify and analyze the magnitude and efforts of combating fake agro-inputs in the developing countries particularly Tanzania. The process of reviewing selected articles was guided by steps defined by Oates [16].

Concepts gathered from the literature were intellectualized by designing a prototype. March \& Smith's framework [17] was used to properly conceptualize and represent all the techniques used in the proposed Agro-inputs Products Verification System (APVS).

Evaluation is invaluable component of the research process [18]. In this study, a qualitative study was carried to evaluate the proposed APVS. The evaluation study helped in determining the applicability and suitability of the prototype in identifying agro-inputs through mobile telephony technologies.

Face to face interview was carried with farmers, agricultural advisors and agro-inputs dealers. The participants were purposefully selected based on their knowledge, experience and roles in agricultural sector. The following formula was used to determine the sample size of the study [19]:

$$
n=\frac{N}{\left(1+N(e)^{2}\right)}
$$

A structured questionnaire was administered to about 90 agricultural stakeholders in Dodoma Urban district to determine their understanding on the course of this study and their readiness to adopt technology based models such as APVS.

\section{RESULTS}

\subsection{Magnitude of agro-inputs counterfeit problem}

The participants in the data collection process rated the magnitude of the fake agro-inputs to be of an alarmingly high level. Figure 1 illustrate the magnitude of agro-inputs as perceived by the respondents. About $73.5 \%$ of all respondents considered the problem to be serious. This magnitude calls for prompt action to curb the counterfeit problem in agro-inputs products. Interestingly $90 \%$ of the participants showed their readiness in adopting the technology based solution for reducing the magnitude of the problem.

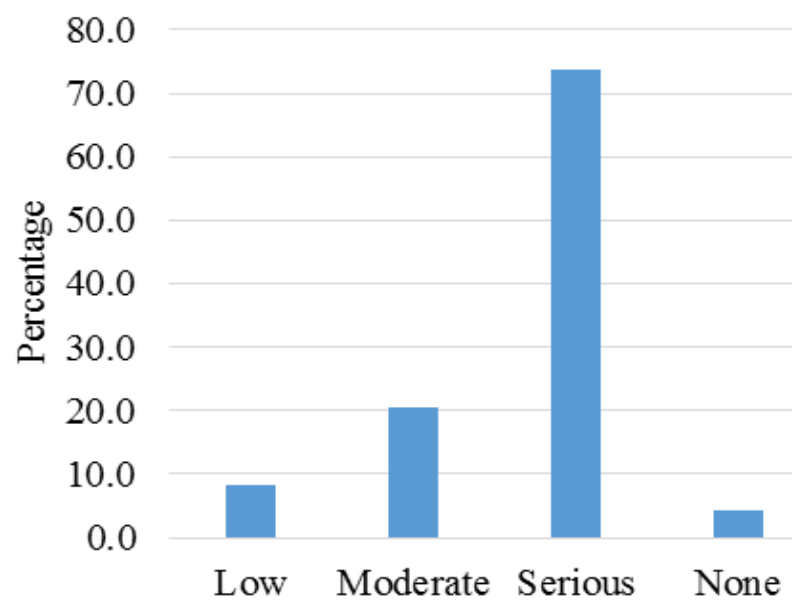

Figure 1: Magnitude of counterfeit agro-inputs

\subsection{Mostly counterfeited agro-inputs}

The results of field data collection show crop seeds are highly counterfeited, making about $46.8 \%$ of the common used agricultural inputs as depicted in Figure 2. This gives an indication that the war against fake agro-inputs should start with securing the crop seeds supply chain. 


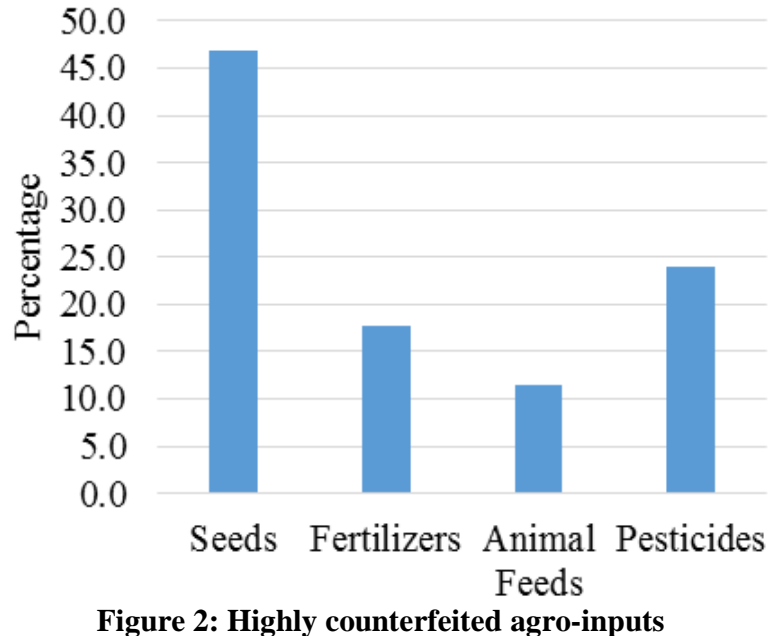

\subsection{Current practices}

The field data collection carried in this study did not find any technology-based tool to verify agro-inputs products in Tanzania. When the respondents were asked what they do to detect the counterfeit agro-product, only $48 \%$ indicated to be aware of at least one method for verifying agro-inputs authenticity. Within them, $19.1 \%$ used expiration date, $17.1 \%$ used manufacturer (brand) and 52\% does not check anything to validity the authenticity of agro-inputs product. Figure 3 shows the methods which are used to verify agroinputs products.

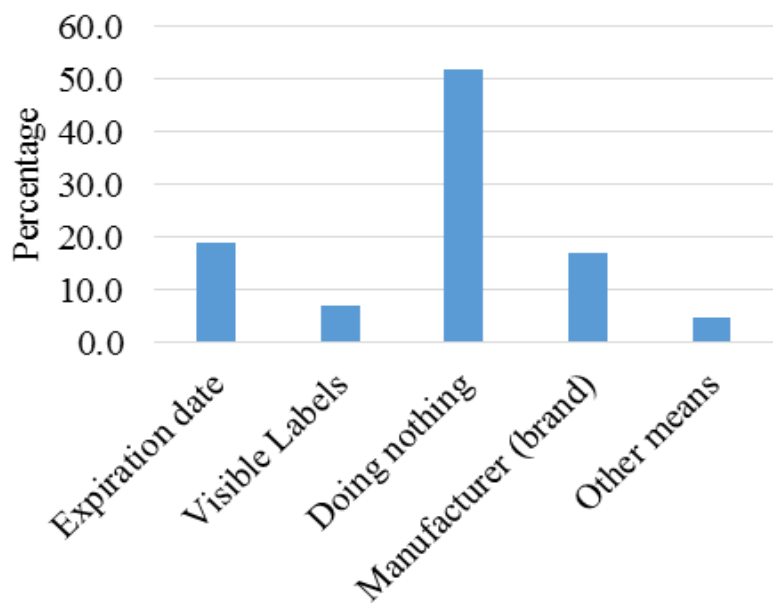

Figure 3: Methods used to verify agro-inputs authenticity

Table 1 describes drawbacks of the current practices used by the community and regulatory authorities to verify agroinputs authenticity. Due to these drawbacks, there have been efforts of combating counterfeit agro-inputs. However, the current efforts encounter gaps which need to be bridged to ensure availability of genuine agro-inputs products.
Table 1: Current practices on verifying agro-inputs products

\begin{tabular}{|c|c|c|}
\hline SN & Current Practice & $\begin{array}{l}\text { Weakness } \\
\text { /Drawback }\end{array}$ \\
\hline 1 & $\begin{array}{l}\text { The use of expiration dates to } \\
\text { validate agro-inputs products }\end{array}$ & $\begin{array}{l}\text { - The large } \\
\text { community is } \\
\text { illiterate } \\
\text { - Expiration } \\
\text { dates can be } \\
\text { easily forged }\end{array}$ \\
\hline 2 & $\begin{array}{l}\text { The use of difference in price } \\
\text { and sources of agro-inputs } \\
\text { products. }\end{array}$ & $\begin{array}{l}\text { - Easy to forge } \\
\text { the sources. }\end{array}$ \\
\hline 3 & $\begin{array}{l}\text { The use of packaging style } \\
\text { and visible labels. }\end{array}$ & $\begin{array}{l}\text { - These metrics } \\
\text { are weak and } \\
\text { can be forged } \\
\text { easily. }\end{array}$ \\
\hline
\end{tabular}

\subsection{Related work}

Several scholars have attempted to propose technology based solutions to combat fake agro-inputs products in the supply chain.

The study by Karanja and Warigia [10] indicates technology as a major tool used by counterfeiters to alter agro-inputs. Counterfeiters are technology savvy and they use it to produce packaging material either similar or better looking than for genuine products. Furthermore, lack of awareness among farmers on how to distinguish fake from genuine give powers to counterfeiters to infringe the supply chain.

Devadas et al. [20] have investigated the use of RFID technology to combat counterfeit agro-inputs. RFID has proved to be effective in fighting counterfeit in many facets such as agro-inputs counterfeit and other products. However, implementation of RFID based product authentication seems to be expensive and could be hard to takeoff in low economy countries such as Tanzania.

Rudolf and Cam [14] and Beaver et al [21] have introduced a mobile based for verifying pesticides in Uganda. The initiatives seemed to be effective in combating fake pesticides. This study attempts to investigate and analyze the magnitude of fake agro-inputs products and understanding the users' behavior on adopting technologybased solution for curbing the problem in Tanzania

Several product authentication technologies exist in the market. Primarily, these technologies can be used in three different ways; tamper proof packaging, product authentication and track and trace technology [22]. Selection of appropriate technology depends on the context.

With the great adoption of mobile phones in Tanzania [23] and in the world [24], mobile based techniques could be feasible. Several scholars have considered mobile phones as a platform for agricultural information dissemination [25], [26] and tool for facilitating banking services [27]. 


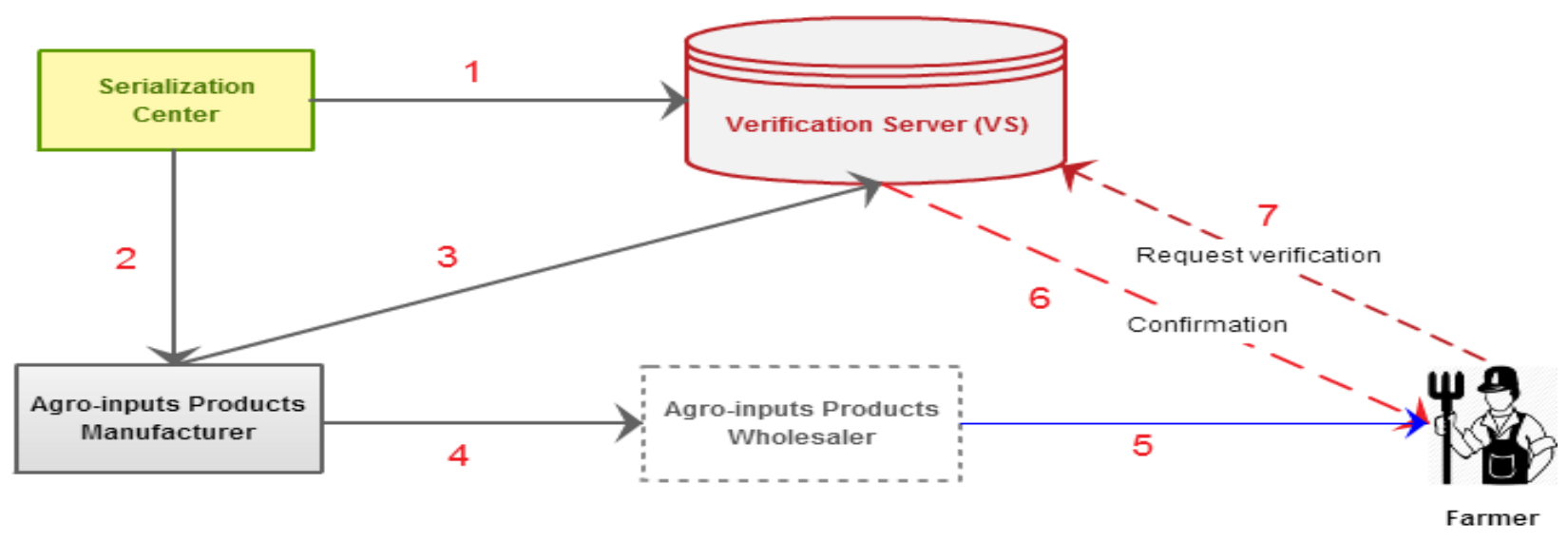

Figure 4: Agro-inputs products verification process

\subsection{Proposed agro-inputs product verification system}

Technology-based solutions could be one of the strategies in curbing the existence of counterfeit agro-inputs in Tanzanian agricultural sector. The proven adoption of ICTs especially mobile technology could be leveraged to enable laws and regulation enforcement, raise community awareness so as to increase the vigilance of the public on the quality of agro-inputs.

Furthermore, technology can help farmers and practitioners enable to verify authenticity of agro-input products, enable data driven decision and policy making process and eventually realization of a sustainable food security in Tanzania. Figure 4 presents a proposed prototype that ensure the authenticity of the agro-inputs products.

The Agro-inputs Products Verification System (APVS) allows the agro-stakeholders to authenticate the genuineness of the agricultural inputs through their mobile phones. Upon purchase of agro-input the customer scratch a secret code which is affixed with the agro-input package. The customer sends the scratch secret code to a verification server (VS) via SMS. The VS prompt a response regarding the authenticity of the seed through an affirmative response and provide agricultural tips regarding the verified agro-input

\subsubsection{How APVS operate}

1. The agro-inputs registrar (regulators) registers the agro-inputs products before they enter the supply chain. The registrar generates unique product code for each product type. This codes are stored in the verification server.

2. Serialization Center: The generated unique product codes (serial numbers) are sent to agroinput products manufactures where they can affix them in the product package.

3. Agro-inputs products manufacturer: The agroinputs products manufacturer affixes the unique serial numbers to each of its products and before they release the products they send the serial number to the verification server to activate the verification process.

4. Agro-inputs products manufacturer: The manufacturers sign their products by affixing serial numbers in their product packages. The signed products are then sent to wholesalers where farmers purchase them.

5. Farmers: Upon purchase farmers verify the products by sending an SMS containing serial numbers which are affixed in the product package.

6. Agro-inputs product verification: The verification server contains all product codes and serial numbers of all signed products. This server finds a match for authentic products.

7. Agro-inputs product verification: The server provides confirmation to farmer via SMS. Furthermore, upon confirmation the server also provides SMS with agricultural advice to farmers.

\subsubsection{Evaluation}

Evaluation is an invaluable component of the research process. Hevner et al.[18], mentions different ways in which IT artifacts can be evaluated, the ways are functionality, completeness, usability, consistency, accuracy, performance, reliability and how it fit with the context. In this study a formative evaluation was performed to determine the feasibility and the farmer perception on the proposed APVS.

The farmers and other agricultural practitioners such as agro-advisors (Bwana Shamba) were interviewed and a structured questionnaire was used to collect their opinions. A total of 90 people participated in our evaluation study.

Overall feedback from participants' show $90 \%$ is early to learn new methods such as APVS to authenticate the agroinputs before applying them in their farms. However, there are still enormous hills to climb in changing mindsets of the practitioners on embracing the emerging technologies particularly mobile technology in fighting against counterfeit agro-input products. This study calls for government efforts in adopting technology based models such as APVS and engaging key stakeholders in implanting and enforcing policies that will assure sustainable agricultural outcomes.

\subsection{Discussion}

This paper has investigated the use of mobile phones as a tool for farmers in verifying the authenticity of the agroinputs products. The great adoption of mobile phones among in the developing countries could be significantly 
used to facilitate agro-inputs verification. Despite the scholarly work on combating the fake agro-inputs products, more work is needed to bridge gaps. The proposed APVS promote stakeholders engagement in the war against counterfeit agro-input products.

\section{CONCLUSION AND FUTURE WORK}

The use of mobile technologies, specifically cheap short text messaging services (SMS), could significantly be leveraged to support agro-inputs products verification. Empowering farmers with a way of verifying the authenticity of the agro-inputs such as seeds, fertilizers and pesticides could greatly motivate farmers to adopt modern practices such as planting hybrid seeds instead of replanting their own seeds.

This can therefore help farmers to increase their productivity and ensure food security. The artifact proposed in this paper can significantly promote efforts of combating fake agro-inputs. The APVS can be implemented in different scales ranging from regional to national levels.

Future work should investigate how the algorithm for signing and verifying agro-inputs can be optimized significantly. Furthermore, studies should also take on board the proposed APVS design in implementation phase and evaluate its effectiveness.

\section{ACKNOWLEDGEMENT}

The authors express their thanks to colleagues and friends who supported and motivated them during the write up of this paper. Furthermore, the authors are gratefully for the comments and feedback from the reviewers.

\section{REFERENCES}

[1] WorldBank, "Fact Sheet: The world Bank and Agriculture in Africa." .

[2] URT, "2012 Population and Housing Census," 2013.

[3] FAO, "Review of food and agricultural policies in the United Republic of Tanzania 2005-2011,” 2013.

[4] URT, “( IMPLEMENTATION FRAMEWORK ) PILLAR No . 1 NATIONAL VISION ON KILIMO KWANZA," 2010.

[5] ITU, "ICTs and Food Security," 2009.

[6] R. Chapman, T. Slaymaker, and J. Young, "Livelihoods Approaches to Information and Communication in Support of Rural Poverty Elimination and Food Security," 2010.

[7] S. N. Meera, A. Jhamtani, and D. U. M. Rao, INFORMATION AND COMMUNICATION TECHNOLOGY IN AGRICULTURAL DEVELOPMENT : A COMPARATIVE ANALYSIS OF THREE PROJECTS FROM INDIA Shaik. N. Meera, Anita Jhamtani, and D.U.M.Rao, no. 135 . AGREN, 2004, pp. 2-15.

[8] URT, "AGRICULTURAL MARKETING POLICY," 2008 .

[9] L. Edda Tandi, "BRIDGING THE AGRICULTURAL KNOWLEDGE AND INFORMATION DIVIDE: THE CASE OF SELECTED TELECENTERS AND RURAL RADIO IN TANZANIA," Electron. J. Inf. Syst. Dev. Coiuntries, vol. 43, no. 6, pp. 1-14, 2010.
[10] A. W. Karingu and P. Karanja, "DETERMINANTS OF THE INFILTRATION OF COUNTERFEIT AGRO-BASED PRODUCTS IN KENYA: A CASE OF SUPPLIERS IN NAIROBI," Int. J. Hum. Resour. Procure., vol. 1, no. 5, pp. 1-14, 2013.

[11] WHO and FAO, "2ND FAO/WHO JOINT MEETING ON PESTICIDE MANAGEMENT,” 2008.

[12] F. Fishel, "Global Counterfeit Pesticide Problems on the Rise," THE GROWER, 2009. .

[13] L. Ediger, "Seeding Positive Impacts: How Business and Civil Society Can Contribute to the Sustainability of Chinese Agriculture," no. May. pp. 1-18, 2010.

[14] G. Rudolf and D. Cam, "The problem of Counterfeit and Illegal Pesticides in Africa Middle East," 2013.

[15] In2eastafrica.net, "Tanzania Govt, farmers cautioned against imported fake pesticides," in2eastafrica.net, 2012. .

[16] B. J. Oates, "Researching Information Systems in Computing," in Reviewing the Literature, London: SAGE Publications, 2006, pp. 187-199.

[17] S. T. March and G. F. Smith, "Design and natural science research on information technology," Decis. Support Syst., vol. 15, pp. 251-266, 1995.

[18] J. P. Alan R. Hevner, Sudha Ram, Salavatore T. March, "Design Science Information," MIS Q., vol. 28, no. 1, pp. 75-105, 2004.

[19] T. Yamena, Statistics, an Introductory Analysis, 2nd Editio. New York, USA, 1967.

[20] S. Devadas, E. Suh, S. Paral, R. Sowell, T. Ziola, and V. Khandelwal, "Design and Implementation of PUFBased 'Unclonable' RFID ICs for Anti-Counterfeiting and Security Applications," in 2008 IEEE International Conference on RFID, 2008, pp. 58-64.

[21] C. Beaver, C. Greene, S. Mall, M. Morris, A. Thigpen, L. Thigpen, and C. Thwaite, "An update on the work and progress of IFDC," 2013.

[22] D. BANSAL, S. MALLA, K. GUDALA, and P. TIWARI, "Anti-Counterfeit Technologies: A Pharmaceutical Industry Perspective," Sci. Pharm., 2013.

[23] TCRA, "Quartely Telecom Statistics Quarter 2 ( December 2013 ) Report 1 . Voice Prepaid Tariffs ( Without TAX )," 2013.

[24] ITU, "The World in 2013 ICT Facts and Figures," 2013.

[25] M. Gakuru, K. Winters, and F. Stepman, "Innovative Farmer Advisory Services Using ICT," in IST-Africa 2009 Conference Proceedings, 2009, pp. 1-11.

[26] A. I. Scott, M. . R. Joseph, and E. D. Dewolf, "The Establishment of a National Pest Information Platform for Extension and Education," Plant Heal. Prog., vol. 1, no. 1, pp. 1-7, 2006.

[27] A. Chan and T. Jia, "The Role of Mobile Banking in Facilitating Rural Finance: Reducing Inequality in Financial Services between Urban and Rural Areas," 2010. 